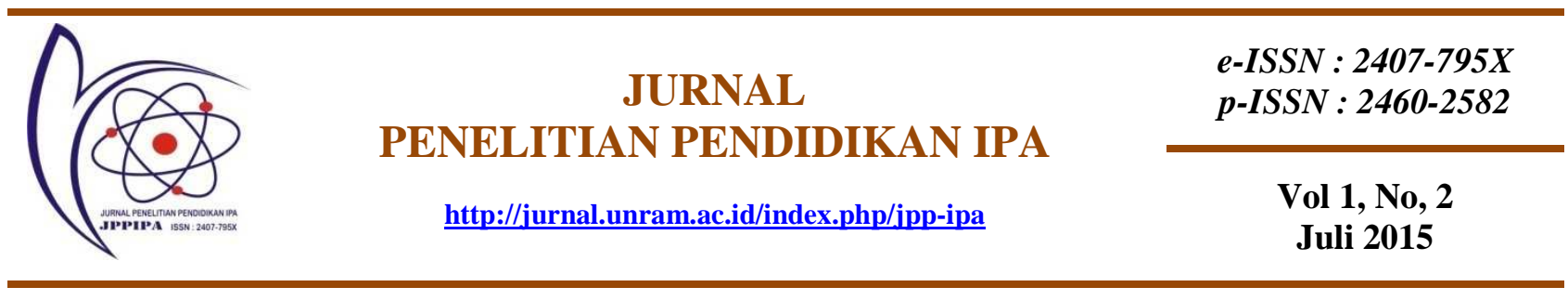

\title{
PENGEMBANGAN PETUNJUK PRAKTIKUM BIOLOGI DAN INSTRUMEN PENILAIAN KINERJA PRAKTIKUM BERBASIS MODEL PEMBELAJARAN KOOPERATIF DAN EFEKTIVITASNYA TERHADAP KEMAMPUAN BERPIKIR KRITIS SISWA SMA/MA KELAS XI
}

\author{
St. Rahmadani ${ }^{1}$, Jamaluddin ${ }^{2}$, Lalu Zulkifli ${ }^{2}$ \\ Program Studi Magister Pendidikan IPA Program Pascasarjana Universitas Mataram ${ }^{123}$ \\ rahma_dhany99@yahoo.com,
}

\begin{tabular}{l} 
Key Words \\
\hline Practical \\
Guidance, \\
Performance \\
assessment, \\
TGT, \\
Performance \\
assessment, \\
Critical \\
Thinking \\
Abilities
\end{tabular}

\begin{abstract}
The aims of this study were: 1) to develop a biology practical guidance based on TGT cooperative models equipped with practical performance assessment instrument; 2) to determine the characteristics and suitability of products than have been developed; 3) to know it's effectiveness in critical thinking abilities on biology subject of students in class XI. Product development process in this study by following Borg and Gall's Development. The result of the expert validation by 3 validators showed that each of the average score in biology practical guidance based on TGT and practical performance assessment instrument were 4,41 and 4,48 and categorized as "very good". Limited testing conducted on 10 students with high, medium, and low ability. The result of limited testing showed that each of percentage score average in biology practical guidance based on TGT and practical performance assessment instrument were 82,67\% and 83,33\% and categorized as "very good". Field trial testing using a pre-test post-test control group design. The data of critical thinking abilities are tested in this study consist of 5 indicator skills: (1) formulate the problem; (2) recognize the existence of a logical relationship between issues; (3) collect and collate information; (4) asses and evaluate the statement of facts; (5) Make some conclude were needed. Data analysis were performed using two independent sample test formula by SPSS 20 for windows. The analysis showed that the critical thinking abilities for indicator 1, 2, 3, and 5 of experimental group different from the control group, while the fourth indicator not different. Data analysis equipped with calculation of the value of n-gain to determine the effectiveness of learning by using product that have been developed. The result of the data analysis showed that the value of n-gain in experimental groupis equal to 0,71 and categorized as "high".
\end{abstract}

\begin{tabular}{l}
\hline Kata Kunci \\
\hline Petunjuk \\
Praktikum, \\
Penilaian \\
Kinerja, \\
Kemampuan \\
Berpikir \\
Kritis
\end{tabular}

Abstrak
Tujuan dari penelitian ini adalah: 1) mengembangkan petunjuk praktikum biologi berbasis model
pembelajaran kooperatif tipe TGT yang dilengkapi dengan instrumen penilaian kinerja praktikum;
2)mengetahui karakteristik dan kelayakan petunjuk praktikum biologi berbasis model
pembelajaran kooperatif tipe TGTyang dilengkapi dengan instrumen penilaian kinerja praktikum;
3)mengetahui efektivitas penerapan produk terhadap kemampuan berpikir kritis peserta didik
pada mata pelajaran Biologi SMA kelas XI. Pengembangan produk dalam penelitian ini mengacu
pada model Borg dan Gall. Hasil pengembangan tersebut telah divalidasi oleh 3 (tiga) orang
validator dengan rata-rata skor untuk petunjuk praktikum dan instrumen penilaian kinerja
berturut-turut 4,41 dan 4,48 yang berkategori "sangat baik". Uji coba terbatas dilakukan
terhadap 10 (sepuluh) orang siswa dengan menunjukkan persentase rata-rata yang diberikan
untuk masing-masing produk berturut-turut $82,67 \%$ dan 83,33\% dengan kategori "sangat baik".
Uji coba diperluas dilakukan pada dua kelas dengan rancangan percobaan pre-test post-test
control-group design.Datakemampuan berpikir kritis yang diuji terdiri atas 5 (lima) indikator: (1)
mengenal masalah; (2) mengenal adanya hubungan logis antar masalah-masalah; (3)
mengumpulkan dan menyusun informasi yang diperlukan; (4) menilai fakta dan mengevaluasi
pernyataan; (5) menarik kesimpulan dan kesamaan-kesamaan yang diperlukan. Analisis data
dilakukan menggunakan rumus uji beda dua sampel dengan bantuan SPSS 20 for windows. Hasil
analisis menunjukkan bahwa ada perbedaan untuk indicator keterampilan proses sains ke 1, 2, 3 ,
dan 5 pada kelas eksperimen dan kelas kontrol, sedangkan indikator ke-4 tidak berbeda. Hasil
analisis data menunjukkan bahwa nilai n-gain pada kelas eksperimen sebesar 0,71 dengan
kategori "tinggi".




\section{PENDAHULUAN}

Sains atau IPA berdasarkan hakekatnya tidak hanya menyangkut isi atau kontennya saja tetapi prosesnya jauh lebih penting. Selain itu, sains memiliki nilai-nilai yang tersirat, sikap dan keterkaitan sains, lingkungan, teknologi, dan masyarakat (salingtemas).Pembelajaran sains yang efektif harus memperhatikan dua hal, yaitu hakekat bagaimana siswa belajar dan hakekat materi yang diajarkan. Hakekat sains meliputi sains sebagai konten, proses, sikap, nilai, dan salingtemas harus tercakup dalam proses pembelajaran. Kenyataan yang ada di lapangan, pembelajaran sains (Fisika, Kimia, dan Biologi) banyak menekankan kepada konten yang berupa konsep-konsep, prinsip-prinsip, dan hukum-hukum di dalam sains (Romlah, 2009). Oleh karena itu, merupakan tanggungjawab para pendidik sains untuk secara cermat memilih model ataupun metode pembelajaran yang tepat sehingga siswa tidak hanya menghafal teori tetapi memiliki keterampilan sains.

Kegiatan Praktikum merupakan bagian dari proses pembelajaran yang bertujuan agar siswa mendapatkan kesempatan untuk menguji dan melaksanakan dalam keadaan nyata apa yang diperoleh dalam teori. Kegiatan praktikum merupakan latihan aktivitas ilmiah yaitu berupa eksperimen, observasi maupun demonstrasi yang menunjukkan adanya keterkaitan antara teori dengan fenomena yang dilaksanakan di laboratorium maupun di luar laboratorium (Rustaman, 2003 dalam Ardli dkk, 2012).

Pada awalnya praktikum dimaksudkan untuk meningkatkan keahlian peserta didik dalam pengamatan, dan meningkatkan keterampilan, serta sebagai sarana berlatih dalam menggunakan peralatan. Di samping itu, bekal pengetahuan awal (pre-requisite knowledge) sebelum melakukan praktikum adalah penting, oleh karena itu bekal ilmu pengetahuan sebelumnya yang tidak cukup menyebabkan siswa sulit mengikuti proses pembelajaran praktikum di laboratorium (Rahayuningsih dan Dwiyanto,2005). Selain itu hasil-hasil riset yang dilaporkan dalam jurnal professional di bidang pendidikan sains dan teknologi serta abstrak disertasi atau skripsi menunjukkan efek positif dari praktikum terhadap pengajaran sains dan teknologi (Rustaman, 2002).

Melihat kenyataan dari pentingnya kegiatan praktikum khususnya dalam pembelajaran IPA, maka proses ini sebaiknya terus dilakukan dengan menambahkan beberapa inovasi-inovasi baru untuk melengkapi kekurangan-kekurangan yang selama ini 
ditemukan dalam kegiatan praktikum. Misalnya praktikum yang berbasis model pembelajaran kooperatif. Slavin (2005) menyatakan bahwa salah satu tipe dari model pembelajaran kooperatif adalah teams games tournament (TGT).Model pembelajaran kooperatif tipe teams games turnamen ini ternyata bisa dikombinasikan dengan kegiatan lainnya. Para guru atau pendidik bisa saja menggunakan TGT untuk satu bagian pengajaran yang mereka lakukan, dan menggunakan metode-metode yang lainnya sebagai pelengkap, misalnya dikombinasikan dengan STAD (student team achievement division), atau dikombinasikan dengan praktik laboratorium. Di samping itu, ia juga menambahkan bahwa tipe TGT ini mampu menambah dimensi kegembiraan bagi siswa.

Produk yang dikembangakan yaitu petunjuk praktikum berbasis pembelajaran kooperatif tipe TGT (teams games tournament) yang dilengkapi dengan instrumen penilaian kinerja praktikum. Petunjuk praktikum yang dikembangkan dilengkapi dengan perlengkapan untuk melakukan permainan (game) akademik setelah melakukan praktikum. Hal ini dimaksudkan agar siswa tidak hanya memahami tehnik dalam berpraktikum tetapi konsep yang terkandung di dalamnya masih dapat diingat dan dipahami.

Penggunaan performance assessment untuk menilai kemampuan siswa memberikan kesempatan lebih kepada mereka untuk terlibat dalam proses pembelajaran. Dengan demikian penggunaan performance assessment dalam kegiatan pembelajaran di kelas menjadikan siswa lebih aktif. Keterlibatan dan keaktifan dalam pembelajaran akan lebih memotivasi siswa dalam memahami materi pembelajaran (Sari dan Wiyarsi, 2011).Sudaryono (2012) menambahkan bahwa penilaian unjuk kerja merupakan penilaian yang dilakukan dengan mengamati kegiatan siswa dalam melakukan sesuatu. Penilaian ini cocok digunakan untuk menilai ketercapaian kompetensi yang menuntut siswa melakukan tugas tertentu seperti praktek di laboratorium.

Melalui penelitian ini, ingin diketahui karakteristik dan kelayakan dari produk serta mengetahui efektifitas penggunaan produk yang dikembangkan terhadap kemampuan berpikir kritis siswa yang terdiri dari 5 (lima) indikator: (1) mengenal masalah; (2) mengenal adanya hubungan logis antar masalah-masalah; (3) mengumpulkan dan menyusun informasi yang diperlukan; (4) menilai fakta dan mengevaluasi pernyataan; (5) menarik kesimpulan-kesimpulan dan kesamaan-kesamaan yang diperlukan. 


\section{METODE}

Prosedur pengembangan yang dilakukan dalam penelitian ini adalah sesuai dengan langkah-langkah berdasarkan model prosedural yang ditetapkan oleh Borg dan Gall (1984). Prosedur dimaksud ditampilkan pada bagan berikut:

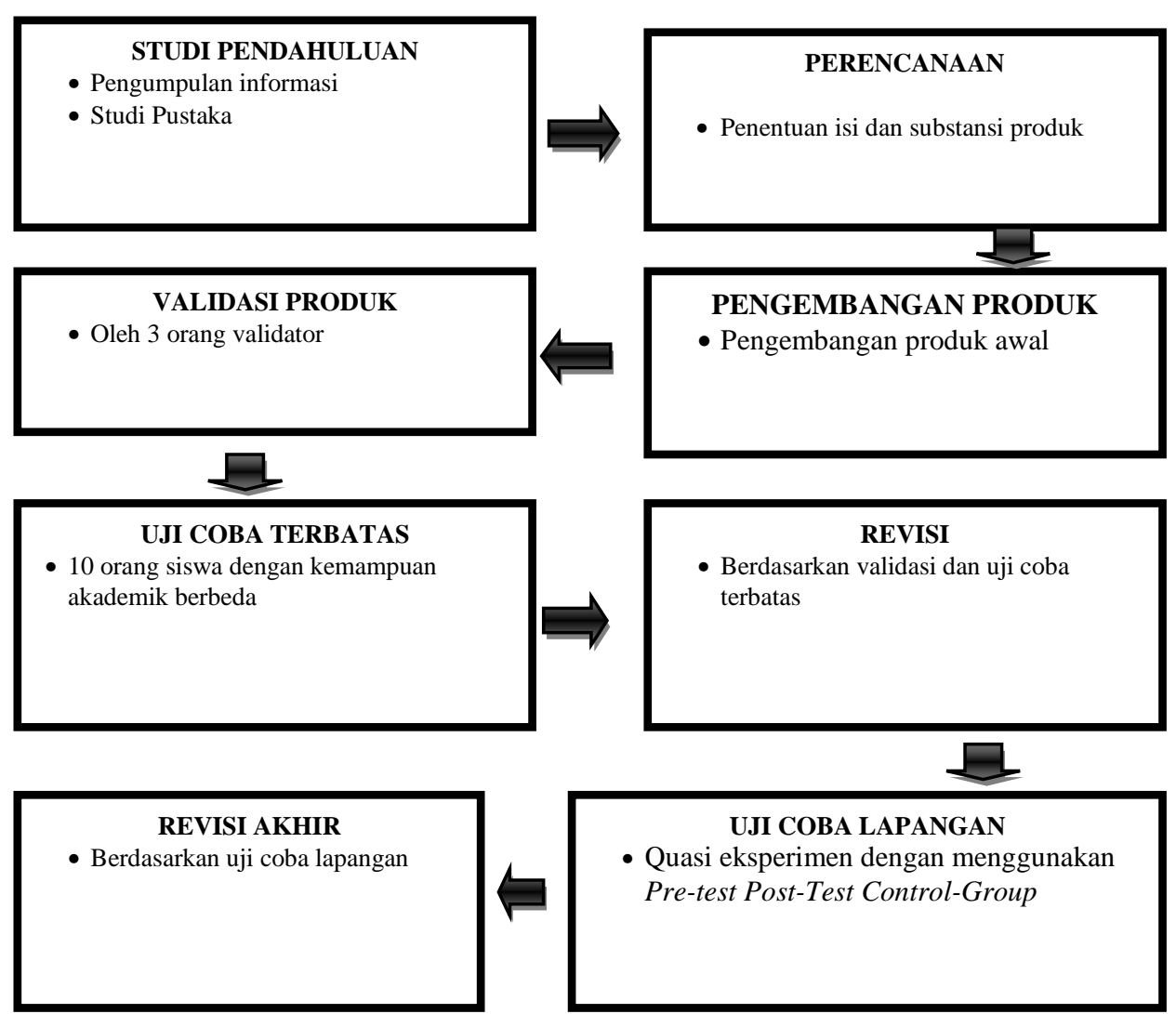

Gambar 1. Bagan alir penelitan: modifikasi Borg dan Gall (1983)

\section{TEKNIK ANALISIS DATA}

\section{Analisis Hasil Validasi Petunjuk Praktikum Berbasis TGT yang Dilengkapi} dengan Instrumen Penilaian Kinerja Praktikum

Teknik analisis data untuk kelayakan produk pembelajaran dilakukan dengan langkahlangkah sebagai berikut:

a) Tabulasi semua data yang diperoleh dari para validator dan menghitung skor total rata-rata dari setiap komponen yang divalidasi dengan rumus:

$$
\bar{X}=\frac{\sum X}{n}
$$




$$
\begin{aligned}
& \text { Keterangan }: \mathrm{X}=\text { skor rata-rata } \\
& \qquad \mathrm{X}=\text { jumlah skor } \\
& \mathrm{n}=\text { jumlah penilai }
\end{aligned}
$$

b) Mengubah skor rata-rata menjadi nilai dengan kriteria. Untuk mengetahui kualitas produk hasil pengembangan maka data yang mula-mula berupa skor, diubah menjadi data kualitatif (data interval) dengan skala lima. Acuan pengubahan skor menjadi skala lima menurut Widoyoko (2009) dalam Prasetyo (2011) dapat dilihat pada tabel 1 .

Tabel 1.Kriteria Nilai Rerata Skor Validasi Produk

\begin{tabular}{ccc}
\hline Interval Skor & Nilai & Kategori \\
\hline$>4,20$ & $\mathrm{~A}$ & Sangat Baik \\
$3,41-4,20$ & $\mathrm{~B}$ & Baik \\
$2,61-3,40$ & $\mathrm{C}$ & Cukup \\
$1,81-2,60$ & $\mathrm{D}$ & Kurang \\
$<1,80$ & $\mathrm{E}$ & Sangat Kurang \\
\hline
\end{tabular}

(Prasetyo, 2011)

\section{Analisis Validasi Perangkat Pembelajaran Pendukung}

Minarno dan Pramukantoro (2013) merincikan langkah-langkah validasi tersebut sebagai berikut :

a) Menentukan jumlah total nilai tertinggi validator. Selanjutnya menentukan jumlah total jawaban validator dengan mengalikan jumlah validator pada tiap-tiap penilaian kualitatif dengan bobot nilainya, kemudian menjumlahkan semua hasilnya. Rumus yang digunakan untuk menentukan jumlah total nilai tertinggi validator adalah sebagai berikut:

$$
\sum \text { nilai tertinggi validator }=\mathrm{n} \times \mathrm{p}
$$

Keterangan :

$$
\begin{array}{ll}
\sum \text { nilai tertinggi validator } & =\text { Jumlah total nilai tertinggi validator } \\
\mathrm{n} & =\text { Banyaknya validator } \\
\mathrm{p} & =\text { bobot nilai tertinggi pada lembar validasi }
\end{array}
$$

b) Hasil Rating

Langkah berikutnya adalah menentukan hasil rating dengan rumus:

$$
\mathrm{HR}=\frac{\sum \text { jawabanvalidator }}{\sum \text { nilai tertinggi validator }} \times 100 \%
$$


Keterangan :

HR

$\sum$ jawaban validator

$\sum$ nilai tertinggi validator
= Hasil Rating jawaban validator.

$=$ jumlah total jawaban validator.

$=$ jumlah total nilai tertinggi validator

c) Konversi Hasil Rating ke dalam tabel berikut :

Tabel 2.Kriteria Penilaian validitas perangkat pembelajaran

\begin{tabular}{cc}
\hline Hasil Rating & Kriteria \\
\hline $0 \%-20 \%$ & Sangat Tidak Valid \\
$21 \%-40 \%$ & Tidak Valid \\
$41 \%-60 \%$ & Kurang Valid \\
$61 \%-80 \%$ & Valid \\
$81 \%-100 \%$ & Sangat Valid \\
\hline
\end{tabular}

\section{Analisis Angket}

Angketyang diisi oleh siswa pada uji coba terbatas dianalisis dengan cara sebagai berikut :

$$
p=\frac{\text { Skoryangdiperoleh }}{\text { Skorideal }} \times 100 \%
$$

Keterangan :

$p=$ Persentase jumlah jawaban responden

(Minarno dan Pramukantoro, 2013)

\section{Analisis $N$-gain}

Untuk analisis efektivitas pembelajaran siswa dilakukan perhitungan nilai gain standar. Perhitungan gain standar mengacu pada persamaan yang dikemukan oleh Meltzer (2002) dalam Prasetyo (2011). Persamaan untuk teknik tersebut adalah sebagai berikut:

$$
\text { GainStandar }=\frac{\text { SkorPosttest }- \text { SkorPretest }}{\text { SkorMaksimum }- \text { SkorPretest }}
$$

(Prasetyo, 2011)

\section{Analisis Kemampuan Berpikir Kritis}

Untuk menguji perbedaan kemampuan berpikir kritis pada siswa kelas kontrol dan kelas eksperimen, maka dibuat hipotesis dan untuk mengujinya digunakan statistik 
uji-t atau dengan uji Mann-Whitney (jika memenuhi syarat statistik non parametris) . Penggunaan teknik statistik uji-t memerlukan prasyarat yang harus dipenuhi, antara lain normalitas dan homogenitas data. Uji beda dilakukan dengan bantuan SPSS 20 for windows.

Kriteria penerimaan atau penolakan $\mathrm{H}_{0}$ pada taraf signifikansi 5\% dengan menggunakan uji-t. $\mathrm{H}_{0}$ ditolak apabila $t_{\text {hitung }}$ lebih besar daripada harga $t_{\text {tabel }}$ dengan derajat bebas $n-1$. Penerimaan atau penolakan $\mathrm{H}_{0}$ juga dapat dilihat melalui probabilitas (signifikansi) yaitu apabila probabilitas (signifikansi) $>0,05$ maka $\mathrm{H}_{0}$ diterima, demikian sebaliknya jika probabilitas (signifikansi) $<0,05$ maka $\mathrm{H}_{0}$ ditolak. Data yang akan dibandingkan dalam penelitian ini adalah nilai keterampilan proses sains peserta didik kelas eksperimen dengan kelas kontrol. Data yang akan dibandingkan dalam penelitian ini adalah nilaikemampuan berpikir kritis siswa kelas eksperimen dengan kelas kontrol.

\section{HASIL DAN PEMBAHASAN}

Produk utama yang dikembangkan adalah petunjuk praktikum berbasis TGT yang kemudian dilengkapi dengan instrumen penilaian kinerja praktikum. Hasil pengembangan petunjuk praktikum berbasis TGT memiliki kriteria sebagai berikut: 1) memiliki sintaks kegiatan praktikum laboratorium yang mengacu pada model pembelajaran kooperatif tipe TGT; 2) dilengkapi dengan kegiatan untuk memberi penguatan terhadap ingatan siswa mengenai konsep dari materi yang dipraktikumkan; 3) dilengkapi dengan kartu yang digunakan dalam turnamen akademik; dan 4) memuat instrumen penilaian kinerja untuk setiap kegiatan yang dipraktikumkan.

Produk yang telah dikembangkan divalidasi oleh validator untuk mengetahui kelayakan dari produk tersebut.Hasil validasi produk utama dan produk pendukung pembelajaran ditampilkan berturut-turut pada Tabel 3 dan Tabel 4.

Tabel 3. Hasil Validasi Ahli Terhadap Produk Hasil Pengembangan

\begin{tabular}{llcc}
\hline No. & Produk & $\begin{array}{c}\text { SKor } \\
\text { Validasi }\end{array}$ & Kriteria \\
\hline 1. & $\begin{array}{l}\text { Petunjuk Praktikum } \\
\text { berbasis TGT }\end{array}$ & 4,41 & Sangat Baik \\
2. & $\begin{array}{l}\text { Instrumen Penilaian } \\
\text { Kinerja }\end{array}$ & 4,48 & Sangat Baik \\
\hline
\end{tabular}


Tabel 4. Hasil Validasi Ahli Terhadap perangkat-perangkat pendukung

\begin{tabular}{|c|c|c|c|}
\hline No. & Perangkat & $\begin{array}{l}\text { Persentase } \\
\text { Skor }\end{array}$ & Kriteria \\
\hline 1. & RPP kelas eksperimen & $89,2 \%$ & Sangat valid \\
\hline 2. & RPP kelas kontrol & $88,4 \%$ & Sangat valid \\
\hline 3. & LKS kelas eksperimen & $89,6 \%$ & Sangat valid \\
\hline 4. & LKS kelas kontrol & $89,6 \%$ & Sangat valid \\
\hline 5. & $\begin{array}{l}\text { Petunjuk praktikum } \\
\text { kelas kontrol }\end{array}$ & $88,1 \%$ & Sangat valid \\
\hline 6. & $\begin{array}{l}\text { Instrumen soal } \\
\text { keterampilan proses } \\
\text { sains }\end{array}$ & $89,2 \%$ & Sangat valid \\
\hline 7. & $\begin{array}{l}\text { Instrumen soal } \\
\text { kemampuan berpikir } \\
\text { kritis }\end{array}$ & $89,7 \%$ & Sangat valid \\
\hline
\end{tabular}

Berdasarkan Tabel 3 dan Tabel 4 di atas, dapat diketahui bahwa produk yang telah dikembangkan memiliki skor validasi lebih dari 4,20 $(>4,20)$ sehingga dinilai layak untuk diterapkan. Begitu pula halnya dengan perangkat-perangkat pendukung memiliki persentase skor lebih dari 80\%, dengan kategori "sangat valid".

Produk yang telah divalidasi oleh ahli selanjutnya diujicobakan terhadap siswa. Uji coba terbatas dilakukan terhadap 10 orang siswa dengan kategori kemampuan yang berbeda, yaitu 3 orang berkemampuan tinggi, 4 orang berkemampuan sedang, dan 3 orang lainnya berkemampuan rendah. Hasil uji coba terbatas disajikan pada Tabel 5.

Tabel 5.Rekapitulasi Kesimpulan Hasil Analisis Uji Coba Terbatas Terhadap Produk Yang Dikembangkan

\begin{tabular}{|c|c|c|c|c|}
\hline \multirow{2}{*}{$\begin{array}{c}\text { Kategori } \\
\text { kemampuan } \\
\text { siswa }\end{array}$} & \multicolumn{2}{|c|}{$\begin{array}{c}\text { Persentase } \\
\text { Penilaian } \\
\text { Terhadap Produk }\end{array}$} & \multicolumn{2}{|c|}{ Kriteria produk } \\
\hline & I & II & I & II \\
\hline Tinggi & $82 \%$ & $80 \%$ & Sangat Baik & Baik \\
\hline Sedang & $80 \%$ & $84 \%$ & Baik & Sangat Baik \\
\hline Rendah & $86 \%$ & $86 \%$ & Sangat Baik & Sangat Baik \\
\hline
\end{tabular}

\section{Keterangan :}

- Produk I = Petunjuk Praktikum Berbasis TGT

- $\quad$ Produk II = Instrumen Penilaian Kinerja Praktikum

Hasil uji coba terbatas pada Tabel 5 menunjukkan bahwa para siswa memberikan penilaian positif terhadap petunjuk praktikum berbasis TGT yang dilengkapi dengan instrumen penilaian kinerja hasil pengembangan, dengan persentase skor minimal $80 \%$. 


\section{Analisis Kemampuan Berpikir Kritis}

Analisis kemampuan berpikir kritis dilakukan secara keseluruhan untuk semua indikator secara umum, dan dilengkapi dengan analisis untuk setiap indikator kemampuan berpikir secara khusus.Dari hasil analisis uji normalitas data diketahui bahwa nilai sig. sebesar 0,200 yang berarti lebih besar dari 0,05 sehingga databerkategori normal. Hasil uji homogenitas menunjukkan nilai sig. sebesar 0,058 sehingga data tersebut berkategori homogen (Tabel 6) .Oleh karena itu, analisis dilakukan dengan menggunakan uji-t.

\begin{tabular}{lcc}
\hline & $\begin{array}{c}\text { Uji homogenitas } \\
\text { menggunakan SPSS 20 for } \\
\text { windows }\end{array}$ \\
\cline { 2 - 3 } & F & Signifikansi \\
\hline Kemampuan Berpikir Kritis & 3.705 & 0.058 \\
\hline
\end{tabular}

Hasil statistik uji-t menggunakan SPSS 20 for windows untuk kemampuan berpikir kritis pada Tabel 6 disajikan dalam dua asumsi yaitu varians diasumsikan homogen dan diasumsikan tidak homogen. Dari analisis homogenitas sebelumnya diketahui bahwa nilai uji-t dilihat dengan asumsi data bersifat homogen. Nilai Sig. (2-tailed) diperoleh 0,00 maka kesimpulannya adalah menolak Hipotesis nol. Sehingga dapat ditarik kesimpulan bahwa nilai kemampuan berpikir kritis kelompok eksperimen secara statistik berbeda dengan kelompok kontrol.

Tabel 7. Hasil Uji - $t$ Untuk Kemampuan Berpikir Kritis

\begin{tabular}{llcrr} 
& $\mathrm{t}$ & $\mathrm{df}$ & $\begin{array}{c}\text { Signifikansi } \\
\text { (2-tailed) }\end{array}$ \\
\hline & $\begin{array}{l}\text { Varian diasumsikan } \\
\text { homogen }\end{array}$ & 4.261 & 71 & 0,00 \\
\cline { 2 - 5 } $\begin{array}{l}\text { Kemampuan } \\
\text { Berpikir Kritis }\end{array}$ & $\begin{array}{l}\text { Varian diasumsikan } \\
\text { tidak homogen }\end{array}$ & 4.239 & 61.324 & 0,00 \\
\hline
\end{tabular}

Tabel 8. Hasil uji beda pada masing-masing indikator kemampuan berpikir kritis menggunakan Mann-Whitney U Test

\begin{tabular}{|c|c|c|c|}
\hline No. & $\begin{array}{c}\text { Indikator Kemampuan } \\
\text { Berpikir Kritis }\end{array}$ & Sig. & Keputusan \\
\hline 1. & Mengenal masalah & 0,019 & $\begin{array}{c}H_{o} \text { ditolak } \\
\text { (Ada Perbedaan) }\end{array}$ \\
\hline 2. & $\begin{array}{l}\text { Mengenal adanya hubungan } \\
\text { logis antar masalah-masalah }\end{array}$ & 0,00 & $\begin{array}{c}H_{o} \text { ditolak } \\
\text { (Ada Perbedaan) }\end{array}$ \\
\hline 3. & $\begin{array}{l}\text { Mengumpulkan dan menyusun } \\
\text { informasi yang diperlukan }\end{array}$ & 0,040 & $\begin{array}{c}H_{o} \text { ditolak } \\
\text { (Ada Perbedaan) }\end{array}$ \\
\hline
\end{tabular}




\begin{tabular}{llcc}
\hline 4. & $\begin{array}{l}\text { Menarik kesimpulan dan } \\
\text { kesamaan-kesamaan yang } \\
\text { diperlukan }\end{array}$ & 0,001 & $\begin{array}{c}H_{o} \text { ditolak } \\
\text { (Ada Perbedaan) }\end{array}$ \\
5. & $\begin{array}{l}\text { Menilai fakta dan mengevaluasi } \\
\text { pernyataan }\end{array}$ & 0,089 & $\begin{array}{c}H_{o} \text { diterima } \\
\text { (Tidak Ada Perbedaan) }\end{array}$
\end{tabular}

Berdasarkan Tabel 8 diketahui bahwa untuk kemampuan peserta didik pada indikator 1,2,3, dan 4 berbeda antara kelas eskperimen dan kelas kontrol, tetapi untuk indikator ke-5 (menilai fakta dan mengevaluasi pernyataan) ternyata tidak ada perbedaan pada kedua kelas tersebut. Hal tersebut bisa disebabkan peserta didik kesulitan untuk menjawab soal-soal yang menuntut kemampuan menilai dan mengevaluasi suatu objek tertentu dikarenakan peserta didik cenderung jarang untuk mengasah kemampuan tersebut selama pembelajaran di sekolah.Hal ini didukung oleh pernyataan Gunawan dan Palupi (2010) bahwa kemampuan menganalisis merupakan jenis kemampuan yang banyak dituntut dari kegiatan pembelajaran di sekolah. Berbagai mata pelajaran menuntut peserta didik memiliki kemampuan menganalisis dengan baik. Tuntutan terhadap peserta didik untuk memiliki kemampuan menganalisis sering kali cenderung lebih penting daripada dimensi proses kognitif yang lain seperti mengevaluasi dan menciptakan.

Pada indikator ke-1, 2, 3, dan 4 diketahui adanya perbedaan kelas eksperimen dengan kelas kontrol. Indikator ke-1 yaitu "mengenal masalah", didukung oleh kenyataan bahwa petunjuk praktikum berbasis teams games tournament (TGT) yang digunakan oleh kelas eksperimen tidak hanya memuat prosedur atau langkah kerja praktikum. Dalam petunjuk tersebut dilengkapi dengan informasi-informasi yang dapat membantu peserta didik dalam mengembangkan kemampuan berpikirnya. Misalnya pada lembar" info kita" peserta didik diberikan ulasan-ulasan untuk mengembangkan kemampuan berpikir kritis, termasuk dalam mengidentifikasi suatu permasalahan penelitian dan menginterpretasikan data. Indikator $\boldsymbol{k e - 2}$ yaitu "mengenal adanya hubungan logis antar masalah-masalah", sesuai dengan pendapat yang dikemukakan secara luas oleh para ahli bahwa pembelajaran yang dilakukan dengan melibatkan peserta didik secara aktif untuk melakukan percobaan maupun penemuan secara terbimbing mampu meningkatkan kemampuan peserta untuk berpikir secara logis. Hal ini juga diperkuat oleh penelitan Purwanto dan Sasmita (2013) yang menyimpulkan bahwa model pembelajaran inkuiri terbimbing memiliki pengaruh terhadap kemampuan berpikir logis peserta didik. Indikator $\boldsymbol{k e - 3}$ yaitu "mengumpulkan dan menyusun informasi yang diperlukan”, kemampuan ini kemungkinan disebabkan oleh 
latihan-latihan yang terjadi selama melakukan permainan akademik melalui teams games tournament (TGT) yang menuntut peserta didik untuk menginterpretasi data berdasarkan pemikirannya sendiri. Hal tersebut dipertegas oleh Subali (2009) yang menyatakan bahwa banyak sub aspek yang terkandung dalam keterampilan "mencatat dan merekam data informasi”, salah satunya adalah merekam informasi sederhana dengan mempresentasikannya dalam berbagai macam bentuk. Indikator $k \boldsymbol{e}-\mathbf{4}$ "menarik kesimpulan dan kesamaan-kesamaan yang diperlukan",kemampuan tersebut berbanding lurus dengan kemampuan pada indikator ke-2(mengenal adanya hubungan logis antar masalah-masalah) Hal ini sesuai dengan pendapat Yuwan (2011) yang menyatakan bahwa berpikir dengan logika merupakan cara untuk menarik kesimpulan dari dua buah atau lebih pernyataan, tidak mengandalkan perasaan maupun pengalaman tapi murni dari akal dan bentuk logika formal. Soekadijo (1985) dalam Kertayasa (2011) juga menambahkan bahwa proses berpikir yang didasari dengan logika akan melahirkan penalaran. Penalaran selanjutnya digunakan untuk mengambil kesimpulan. Hal tersebut sesuai dengan hasil penelitian ini yang menyatakan bahwa baik pada indikator ke-2 dan ke-4 sama-sama terjadi perbedaan pada kelas eksperimen dibandingkan dengan kelas kontrol.

Untuk mengetahui efektivitas penggunaan produk dapat dilihat dari nilai N-gain pada kelompok eksperimen dan kelompok kontrol. Menurut Margendoller (2006) dalam Taufik dan Masitoh (2011), suatu pembelajaran dikatakan efektif jika menghasilkan Ngain tinggi. Hasil analisis data menunjukkan nilai $N$-gain pada kelas eksperimen sebesar 0,71 dan berkategori tinggi. Hal ini menunjukkan bahwa penggunaan petunjuk praktikum berbasis TGT yang dilengkapi dengan instrumen penilaian kinerja efektif terhadap kemampuan berpikir kritis peserta didik.

\section{PENUTUP}

Kelayakan dari petunjuk praktikum berbasis TGT (teams games tournament) yang dilengkapi dengan instrumen penilaian kinerja praktikum berkategori "sangat baik" berdasarkan validasi ahli dan uji coba terhadap siswa.

Hasil analisis data menunjukkan bahwa secara umum terdapat perbedaan kemampuan berpikir kritis kelas eksperimen dan kelas kontrol. Di samping itu, nilai Ngain pada kelas eksperimen berkategori "tinggi", yang berarti pembelajaran pada kelas eksperimen berlangsung efektif. 


\section{DAFTAR PUSTAKA}

Ardli, I., A. G. Abdullah, S. Mujdalipah, dan Ana. 2012. Perangkat Penilaian Kinerja Untuk Pembelajaran Teknik Pemeliharaan Ikan Bandung:Jurnal INVOTEC, volume 8, no.2, September 2012 : 147-166.

Borg, W. R. dan Meredith D. G. 1983. Educational Research An Introduction, Fourth Edition. New York : Longman Inc.

Gunawan, I. dan Palupi, A. R. Revisi Ranah Kognitif: Kerangka Landasan Untuk Pembelajaran, Pengajaran, dan Penilaian. http://www.ikippgrimadiun.ac.id/ejournal/sites/default/files/2_Imamgun $\% 20 \& \% 20$ Anggarini_Taksonomi\%20Bloom\%20\%E2\%80\%93\%20Revisi\%20Ranah\%20Kog nitif\%20Kerangka\%20Landasan\%20untuk\%20Pembelajaran,\%20Pengajaran,\%20 $\& \% 20$ Penilaian.pdf

Kertayasa, I. N. 2011. Logika, Riset, dan Kebenaran. WIDYATECH Jurnal Sains dan Teknologi Vol.10 No.3 April 2011.

Minarno, S. A. dan Pramukantoro, J. A. 2013. Pengembangan Perangkat Pembelajaran Active Learning Dengan Strategi Learning Tournament Pada Standar Kompetensi Memperbaiki CD Player Di SMK Negeri 2 Surabaya. Surabaya: Jurnal Pendidikan Teknik Elektro, Volume 2 Nomor 1 Tahun 2013, 333-342.

Prasetyo, Z. K. 2011. Pengembangan Perangkat Pembelajaran Sains Terpadu Untuk Meningkatkan Kognitif, Keterampilan Proses,Kreativitas Serta Menerapkan Konsep Ilmiah Peserta Didik SMP. Yogyakarta: Penelitian Dibiayai Dengan Dana DIPA BLU UNY Tahun Anggaran 2010. Nomor: 1805/UN34.17/LK/2011.

Purwanto, A. dan Sasmita, R. 2013. Pembelajaran Fisika Dengan Menerapkan Model Inkuiri Terbimbing Dalam Menumbuhkan Kemampuan Berpikir Logis Siswa di SMA Negeri 8 Bengkulu.Prosiding Semirata Universitas Lampung 2013.

Rahayuningsih, E. dan Dwiyanto, D. 2005. Pembelajaran Di Laboratorium. Yogyakarta: Pusat Pengembangan Pendidikan Universitas Gadjah Mada.

Romlah.2009. Peranan Praktikum dalam Mengembangkan Keterampilan Proses dan Kerja Laboratorium.Garut:Disampaikan pada pertemuan MGMP Biologi Kabupaten Garut Tanggal 3 Februari 2009.

Rustaman, N. Y. 2002. Perencanaan dan Penilaian Praktikum di Perguruan Tinggi.Bandung : Disiapkan untuk Program Applied Approach Bagi Dosen UPI Tahun 2002.

Sari, L. dan Wiyarsi, A. 2011. Efektivitas Penerapan Performance Assessment Terhadap Motivasi dan Prestasi Belajar Kimia Siswa SMA di Daerah Istimewa Yogyakarta.Surabaya : Prosiding Seminar Nasional Kimia Unesa 2011-ISBN : 978979-028-378-7. 
Slavin. 2005. Cooperatif Learning: Teori, riset dan praktik. Bandung : Nusa Media.

Subali, B. 2009. Pengembangan Tes Pengukuran Keterampilan Proses Sains Pola Divergen Mata Pelajaran Biologi SMA.Yogyakarta : Prosiding Seminar Nasional Biologi, Lingkungan dan Pembelajarannya. Jurdik Biologi, FPMIPA, Universitas Negeri Yogyakarta, 4 Juli 2009.

Sudaryono. 2012. Dasar-dasar Evaluasi Pembelajaran. Yogyakarta : Graha Ilmu.

Taufiq dan Masitoh.2011. Efektivitas Pembelajaran IPA Kelas Tinggi Berbasis Multimedia Interaktif Untuk Meningkatkan Keterampilan Berpikir Kritis Mahasiswa Calon Guru SD. Seminar Nasional Pendidikan MIPA, Unila, 2011.

Yuwan, R. 2011. Keterampilan Berpikir Kritis dengan Prinsip Logika.Makalah IF2091 Struktur Diskrit_Sem.I Tahun 2011/2012. 